The International Journal of Indian Psychology

ISSN 2348-5396 (e) | ISSN: 2349-3429 (p)

Volume 5, Issue 1, DIP: 18.01.121/20170501

DOI: $10.25215 / 0501.121$

http://www.ijip.in | October-December, 2017

Original Research Paper

\title{
Effect of Loneliness on Self Esteem of High School Boys and Girls
}

\author{
A. K. Ashwini ${ }^{1 *}$
}

\section{ABSTRACT}

The present study attempts to examine the effect of loneliness on self esteem of high school boys and girls, and to see if there is any gender difference existing in the feeling of loneliness and level of self esteem among high school boys and girls. The sample for the study comprised of 120 high school students, out of which 60 were boys and 60 were girls between the age range of 11 to 14 years. Test materials used to assess loneliness and self esteem among high school boys and girls are Daniel W.Russell's UCLA Loneliness Scale (Version 3) and Self Esteem Inventory, the school short form developed by Coopersmith, 1967. Obtained data is analyzed by using Pearson's correlation coefficient and T-test. Results revealed that that there is a significant relationship between feeling of loneliness and level of self esteem among high school boys. Where as for the high school girls there is found to be no significant relationship between feeling of loneliness and level of self esteem. With respect to finding the gender difference in feeling of loneliness it is seen that there is no significant difference among high school boys and girls. Similarly the findings for gender difference in the level of self esteem it is seen that there is no significant difference among high school boys and girls.

Keywords: Loneliness, Self Esteem, High School Boys, Girls

All those who have ever experienced a period of loneliness in their life, may already know that these feelings are often accompanied by feelings of low self-esteem. Although loneliness and self-esteem are individual psychological constructs, both are very important aspects of individuals' lives. Loneliness may be described as a negative affect state and "reflects an individual's subjective perception of deficiencies in his or her network of social relationships" (Russell, Cutrona, Rose, and Yurko, 1984). Self-esteem may be defined as feelings of selfworth and self-respect (Rosenberg, 1965). Loneliness has been linked to physical illness (Lynch, 1976), alcoholism (Bell, 1956), and suicide (Wenz,1977). Along the same lines, people with high self-esteem have been found to have fewer ulcers, to experience fewer sleepless nights, to conform less to peer pressure, and to be less likely to use drugs (Brockner \& Hulton, 1978). Also, self-esteem has been found to be a better predictor of satisfaction with one's life than objective characteristics like income or age (Diener, 1984). Both loneliness and low self-esteem have been found to be related to the psychological states of depression

\footnotetext{
${ }^{1}$ Assistant Professor, OUCW. Koti, Hyderabad, India

*Responding Author

(C) 2017 Ashwini A K; licensee IJIP. This is an Open Access Research distributed under the terms of the Creative Commons Attribution License (www.creativecommons.org/licenses/by/2.0), which permits unrestricted use, distribution, and reproduction in any Medium, provided the original work is properly cited.
} 
and hopelessness (Crandall, 1973). Perhaps not surprisingly previous research has shown that loneliness and self-esteem are related (Davis, et al. 1992); specifically, loneliness is negatively correlated with self esteem. The aim of the present research was to study the effect of loneliness on self esteem of high school boys and girls.

\section{Loneliness}

Loneliness is a complex and usually unpleasant emotional response to isolation or lack of companionship. Loneliness typically includes anxious feelings about a lack of connectedness or communality with other beings, both in the present and extending into future. As such loneliness can be felt even when surrounded by other people. The causes of loneliness are varied and include social, mental and emotional factors.

Loneliness is a significant problem that can predispose young children to immediate and long-term negative consequences. However, only recently have research and intervention in educational settings focused on young children who are lonely. It is becoming increasingly clear that many young children understand the concept of loneliness and report feeling lonely. Children who feel lonely often experience poor peer relationships and therefore express more loneliness than peers with friends. They often feel excluded, feeling that can be damaging to their self-esteem. In addition, they may experience feelings of sadness, malaise, boredom, and alienation. Furthermore, early childhood experiences that contribute to loneliness may predict loneliness during adulthood. Consequently, lonely children may miss out on many opportunities to interact with their peers and to learn important lifelong skills. Given the importance placed on the benefits of peer interactions and friendships to children's development, this potential lack of interaction raises many concerns for teachers who work with young children. Peer relations matter to children, and lonely children place as much importance on them as do other children (Ramsey, 1991).

Several factors contribute to feelings of loneliness in young children. Some that occur outside of the school setting are conflict within the home; moving to a new school or neighborhood; losing a friend; losing an object, possession, or pet; experiencing the divorce of parents; or experiencing the death of a pet or significant person. Equally important are factors that occur within the child's school setting, such as being rejected by peers; lacking social skills and knowledge of how to make friends; or possessing personal characteristics (e.g., shyness, anxiety, and low self-esteem) that contribute to difficulties in making friends. Kindergarten children who are victimized by peers (e.g., picked on, or physically or verbally attacked or taunted) report higher levels of loneliness, distress, and negative attitudes toward school than non victimized children (Kochenderfer \& Ladd, 1996).

\section{Self esteem}

Self-esteem is similar to self-worth (how much a person values himself or herself). This can change from day to day or from year to year, but overall self-esteem tends to develop from infancy and keep going until we are adults. 
Self-esteem also can be defined as feeling capable while also feeling loved. A child who is happy with an achievement but does not feel loved may eventually experience low selfesteem. Likewise, a child who feels loved but is hesitant about his or her own abilities can also develop low self-esteem. Healthy self-esteem comes when a good balance is maintained. Self esteem has many aspects and develops within the context of a Childs evolving sense of identity and the ever changing life tasks and challenges he faces. It is a lifelong developmental process whose roots are established in early childhood. A child's sense of identity is developed through their view of acceptance, power, control, competence and moral virtues.

Self-esteem has been examined in relation to a variety of psychological variables. For example, people who are low in self-esteem are at risk for depression and anxiety (Higgins, 1987). Individuals who feel good about themselves are less likely to use drugs and report higher feelings of happiness (Brockner \& Hulton, 1978).

Research has shown key differences between individuals with high and low self-esteem. For example, people with high self-esteem focus on growth and improvement, whereas people with low self-esteem focus on not making mistakes in life. Low self-esteem has been shown to be correlated with a number of negative outcomes, such as depression (Silverstone, \& Salsali, 2003).

Rosenberg, \& Owen (2001) offers the following description of low self-esteem people based on empirical research. People with low self-esteem are more troubled by failure and tend to exaggerate events as being negative. For example, they often interpret non critical comments as critical. They are more likely to experience social anxiety and low levels of interpersonal confidence. This in turn makes social interaction with others difficult as they feel awkward, shy, conspicuous, and unable to adequately express themselves when interacting with others . Furthermore, low self-esteem individuals tend to be pessimistic towards people and groups within society.

\section{Objectives}

1. To determine the influence of loneliness on self esteem of high school boys

2. To determine the influence of loneliness on self esteem of high school girls

3. To study the gender difference in feeling of loneliness among high school boys and girls.

4. To study the gender difference in level of self esteem among high school boys and girls.

\section{Hypotheses}

1. There will be a significant relationship between loneliness and self esteem of high school boys.

2. There will be significant relationship between loneliness and self esteem of high school girls. 
3. There will be a significant difference in feeling of loneliness among high school boys and girls.

4. There will be a significant difference in the level of self esteem among high school boys and girls.

\section{Sample}

The sample for the research consists of 120 high school students, out of which 60 were boys and 60 were girls. Selected students were between $7^{\text {th }}$ to $10^{\text {th }}$ class, with the age range of 11 to 14 years respectively. The sample selection was done through purposeful sampling. All the students completed the test genuinely.

\section{Tools used}

1. Daniel W.Russell's UCLA Loneliness Scale (Version 3) was used to measure loneliness among children.

2. Self Esteem Inventory. The school short form developed by Coopersmith ,1967 was used to measure level of self esteem.

\section{Procedure}

The students from $7^{\text {th }}$ to $10^{\text {th }}$ class were identified and selected on the basis of gender. The selected sample was then given the two scales one after the other. The students were requested to read the instructions which were clearly printed on each of the two scales, and choose the most suitable alternative which are given on the two scales. The time taken for completing the two scales was approximately 30 minutes. Later the scales were collected back and scored according to the given keys, and further statistical methods were implemented for analysis of the results and discussion.

\section{Statistical techniques}

The data obtained was analyzed using Pearson's Correlation Coefficient and' $t$ ' test.

\section{RESULTS AND DISCUSSION}

Table:1 Mean, SD of high boys and girls for loneliness and self esteem respectively.

\begin{tabular}{|l|l|l|l|l|}
\hline \multicolumn{3}{|l|}{ BOYS (N=60) } & GIRLS (N=60) \\
\hline & MEAN & SD & MEAN & SD \\
\hline Loneliness & 41.88 & 2.733 & 41.66 & 2.660 \\
\hline Self esteem & 55 & 24.46 & 58.86 & 14.106 \\
\hline
\end{tabular}

Table: 2 Shows relationship between loneliness and self esteem among high school boys and girls using Pearson's correlation method.

\begin{tabular}{|l|l|l|l|}
\hline & Self esteem Boys (N=60) & Self esteem Girls (N=60) & Remarks \\
\hline Loneliness Boys (N= 60) & -0.51324 & & $*$ \\
\hline Loneliness Girls (N=60) & & -0.03928 & NS \\
\hline$* \mathrm{P}<.05$ \\
$\mathrm{NS}=$ Not significant
\end{tabular}

(c) The International Journal of Indian Psychology, ISSN 2348-5396 (e)| ISSN: 2349-3429 (p) | 8 
Table 2: Shows the correlation between loneliness and self esteem in high school boys using Pearson correlation coefficient. Based on the values it is inferred that correlation of high school boys for feeling of loneliness and level of self esteem is found to be -0.51324 which is significant at $\mathrm{P}<.05$ level. The mean of high school boys for loneliness and self esteem is found to be $\mathrm{M}=41.88$ and $\mathrm{M}=55$ respectively. And the SD of high school boys for loneliness and self esteem is found to be $\mathrm{SD}=2.733$ and $\mathrm{SD}=24.46$ (Table no -1). Here it can be seen that there is a significant and moderate level of negative relationship between feeling of loneliness and level of self esteem. This depicts that when feelings of loneliness is found to be high among the high school boys it has impacted on the decrease in the level of their self esteem, where as when feelings of loneliness is found to be low among the high school boys then the level of self esteem is found to be high.

This indicates that loneliness does have an influential impact on the level of self esteem among high school boys. As high school boys during this stage are more influenced by peer pressure and parental expectations in order to form their identity and position in the society by belonging to their respective groups. Along with these pressures if the boys are found to be lonely then the multitudinal impact of all these factors would negatively have an impact on their level of self esteem. In other researches and interventions it is found that children who feel lonely often experience poor peer relationships and therefore express more loneliness than peers with friends. They often feel excluded, which is a feeling that can be damaging to their self esteem and worth. Thus it leads to acceptance of the hypothesis i.e., there will be a significant relationship between loneliness and self esteem of high school boys.

The results in Table- 2 shows the correlation between loneliness and self esteem in high school girls using Pearson correlation coefficient. Based on the values it is inferred that correlation of high school girls for feeling of loneliness and level of self esteem is found to be -0.03928. The mean of high school girls for loneliness and self esteem is found to be $\mathrm{M}=41.66$ and $\mathrm{M}=58.86$ respectively. And the SD of high school girls for loneliness and self esteem is found to be $\mathrm{SD}=2.660$ and $\mathrm{SD}=14.106$ (Table no -1 ). This indicates that there is very slight and negligible negative relationship between feeling of loneliness and level of self esteem, and it was also found to be not significant. Here it is seen that there is no impact of loneliness on self esteem of high school girls. This can lead to an understanding that the high school girls do not analyze their level of self esteem based on feelings of loneliness. There can be some other factors which is even been supported by other researchers that might be affecting the overall behavior and personality development of the high school girls in their early teens i.e. physical appearance, social interactions, scholastic performance and family all play an important role. Thus it leads to the rejection of the hypothesis i.e. there will be significant relationship between loneliness and self esteem of high school girls.

Studies indicate that self esteem decreases slightly for both boys and girls in the transition to middle school. However, during the high school years, boys self esteem increases dramatically while girls self esteem stays about the same. 
Table-3: Mean, SD, and t ratio for loneliness and self esteem among high school boys and girls. $(N=120)$

\begin{tabular}{|l|l|l|l|l|l|}
\hline & N & Mean & SD & t-ratio & Remarks \\
\hline Loneliness & 120 & 41.775 & 8.74 & 1.060 & NS \\
\hline Self esteem & 120 & 56.93 & 13.97 & 0.448 & NS \\
\hline
\end{tabular}

NS = Not significant

Table -3, shows the gender difference in the feeling of loneliness among high school boys and girls with a mean value of $\mathrm{M}=41.775, \mathrm{SD}=8.74$ and with the $t$ ratio of 1.060 , which is found to be not significant. This depicts that there is no gender difference found in the feeling of loneliness among high school boys and girls for this sample studied. So gender difference cannot be considered as a predictor for experiencing of loneliness among high school boys and girls. Thus it leads to rejection of the hypothesis i.e. there will be a significant difference in feeling of loneliness among boys and girls.

Table- 3, shows the gender difference in the level of self esteem among high school boys and girls with a mean value of $\mathrm{M}=56.93, \mathrm{SD}=13.97$ and with the $\mathrm{t}$ ratio of 0.448 , which is found to be not significant. This depicts that there is no gender difference found in the level of self esteem among high school boys and girls for this sample studied. So gender difference cannot be considered as a predicting factor for determining level of self esteem among high school boys and girls. Thus it leads to rejection of the hypothesis i.e. there will be a significant difference in the level of self esteem among boys and girls.

\section{CONCLUSION}

From this research it can be concluded that there was a significant relationship between feeling of loneliness and level of self esteem among high school boys. Where as for the high school girls there was found to be no significant relationship between feeling of loneliness and level of self esteem.

With respect to finding the gender difference in feeling of loneliness it is seen that there is no significant difference among high school boys and girls. Similarly the findings for gender difference in the level of self esteem it is seen that there is no significant difference among high school boys and girls.

\section{REFERENCES}

Bell, RG. (1956). Alcoholism and loneliness. Journal of Social Therapy, 2, 171-181.

Brockner, J., \& Hulton, A.J.B. (1978). How to reverse the vicious cycle of low self-esteem: The importance of attentional focus. Journal of Experimental Social

Psychology, 14, 564-578.

Crandall, R. (1973). The measurement of self-esteem and related constructs. In J.Robinson and P. Shaver (Eds.) Measures of social psychological attitudes. Ann Arbor: University of Michigan, Institute for Social Research. 
Davis, S.F., Hanson, H. Edson, R. \& Ziegler, C. (1992) The relationship between optimismpessimism, loneliness, and level of self-esteem in college students. College Student Journal, 26, 244-247.

Deiner, E. (1984). Subjective well-being. Psychological Bulletin, 95, 542-575.

Higgins, E.T. (1987). Self-discrepancy: A theory relating self and affect. Psychological Review, 94, 319-340.

Kochenderfer, B. J., \& Ladd, G. W. (1996). Peer victimization: Manifestations and relations to school adjustment in kindergarten. Journal of School Psychology, 34(3), 267-283. EJ 537306.

Lynch, J.J. (1976). The broken heart: The medical consequences of loneliness. New York: Basic Books.

Ramsey, P. G. (1991). Making friends in school. New York: Teachers College Press.

Rosenberg, M. (1965). Society and the adolescent self-image. Princeton, NJ: Princeton

Rosenberg, M., \& Owens, T.J. (2001). Low self-esteem people: A collective portrait. In T.J. Owens. S. Stryker, \& N. Goodmanm (Eds.), Extending self-esteem theory and research (pp. 400-436). New York: Cambridge University Press.

Russell, D. Cutrona, C. Rose, J., \& Yurko, K. (1984) Social and Emotional Loneliness: An Examination of Weiss's Typology of Loneliness. Journal of Personality and Social Psychology, 46, 1313-1321.University Press.

Silverstone, P. H., \& Salsali, M. (2003). Low self-esteem and psychiatric patients: Part I-The relationship between low self-esteem and psychiatric diagnosis. Annals of General Psychiatry, 2(1), 2.

Wenz, F.V. (1977). Seasonal suicide attempts and forms of loneliness. Psychological Reports, 40, 807-810.

How to cite this article: Ashwini A K (2017). Effect of Loneliness on Self Esteem of High School Boys and Girls. International Journal of Indian Psychology, Vol. 5, (1), DIP: 18.01.121/20170501, DOI: $10.25215 / 0501.121$ 